\title{
Manifestações Clínicas Atípicas de Infeção Genital pelos Vírus Herpes Simplex e sua Abordagem Terapêutica
}

\author{
Pedro Miguel Garrido', João Borges-Costa ${ }^{1,2,3}$ \\ 'Clínica Universitária de Dermatologia de Lisboa, Centro Hospitalar Lisboa Norte, EPE (CHLN) - Lisboa, Portugal. \\ ${ }^{2}$ Unidade de Investigação em Dermatologia da Faculdade de Medicina da Universidade de Lisboa (FMUL) - Lisboa, Portugal. \\ ${ }^{3}$ Instituto de Higiene e Medicina Tropical, Universidade Nova de Lisboa, Lisboa, Portugal
}

RESUMO - O herpes genital é uma doença sexualmente transmissível com elevada prevalência. As apresentações clínicas atípicas da infeção herpética são raras, mas a sua prevalência aumentou, em relação com o crescente número de indivíduos imunossuprimidos. A terapêutica destas condições é difícil, requerendo maior tempo de tratamento e estando associada a uma importante taxa de resistência aos fármacos anti-virais comumente utilizados. Como alternativas eficazes, salientam-se os anti-virais foscarnet e cidofovir. Neste artigo são abordadas três formas de apresentação cutânea atípica de infeção herpética, selecionadas pela sua relevância na prática clínica: lesões hipertróficas, úlceras crónicas e foliculite herpética.

PALAVRAS-CHAVE - Antivirais; Doenças Virais Sexualmente Transmissíveis; Herpes Genital; Herpes Simples; Infecções Oportunistas Relacionadas com a SIDA.

\section{Atypical Clinical Manifestations of Genital Herpes Simplex Virus Infection and Their Treatment}

ABSTRACT - Genital herpes is a sexually transmitted infection with high global prevalence. Atypical clinical presentations of herpetic infection are rare but are becoming increasingly frequent due to the growing number of immunosuppressed patients. Therapy is challenging, with a longer treatment duration being frequently needed and an important resistance rate to the common anti-viral agents. Foscarnet and cidofovir are effective alternatives. In this article we review three atypical cutaneous presentations of herpetic infection, selected by their relevance in clinical practice: hypertrophic lesions, chronic ulcers and herpetic folliculitis.

KEYWORDS - AIDS-Related Opportunistic Infections; Antiviral Agents; Herpes Genitalis; Herpes Simplex; Sexually Transmitted Diseases, Viral.

\section{INTRODUÇÃO}

O herpes genital é uma doença sexualmente transmissível com elevada prevalência a nível global, causada maioritariamente pela infeção pelo vírus herpes simplex (VHS) tipo 2. Contudo, um número crescente de casos resulta da infeção por VHS tipo 1, sendo que em alguns países este é já o principal agente responsável pelo episódio primário de herpes genital. 1,2

As infeções pelo VHS e pelo vírus da imunodeficiência humana $(\mathrm{VIH})$ são crónicas e sexualmente transmissíveis e os dois vírus têm interações biológicas recíprocas e diretas. $\mathrm{Na}$ presença de infeção herpética crónica estabelecida, o risco de transmissão de VIH está aumentado 2-5 vezes. ${ }^{3}$

As apresentações clínicas atípicas da infeção herpética são raras, mas têm-se observado de forma cada vez mais frequente na prática clínica, em relação com o crescente número de indivíduos imunossuprimidos. Apesar da sua incidência ser maior na presença de infeção pelo $\mathrm{VIH}$,

Prémios / Apresentaçôes: Parcialmente apresentado previamente em 25 th EADV Congress, 28 Set - 2 Out 2016 - Viena, Áustria

Correspondência: Pedro Miguel Clemente Garrido

Serviço de Dermatologia - Hospital de Santa Maria

Av Professor Egas Moniz

1649-028 Lisboa, Portugal.

E-mail: pedro.mi.garrido@gmail.com

DOI: https://dx.doi.org/10.29021/spdv.76.1.847
Recebido/Received

16 Novembro/November 2017

Aceite/Accepted

03 Janeiro/January 2018 


\section{GEIDST}

afetam também indivíduos com transplante de órgão, com leucemia, linfoma ou outra condição hematológica/oncológica e doentes a realizar terapêutica imunossupressora cronicamente. ${ }^{4}$ Embora raro, indivíduos saudáveis, imunocompetentes, podem também desenvolver formas de apresentação atípica. ${ }^{5}$

Nos indivíduos imunocomprometidos, a infeção por VHS está associada a lesões mais graves, com maior extensão tecidual e, por vezes, com necrose. ${ }^{6}$ As manifestações clínicas são, com frequência, crónicas, recorrentes e resistentes aos esquemas terapêuticos convencionais. ${ }^{4}$

Existem vários casos descritos na literatura de manifestações clínicas atípicas de infeção herpética, mas os mais revelantes com envolvimento cutâneo são as lesões hipertróficas, as úlceras crónicas e a foliculite herpética.

\section{LESÕES HERPÉTICAS HIPERTRÓFICAS}

A infeção pelo VHS pode causar lesões de características hipertróficas, verrucosas, nodulares ou pseudo-tumorais, por vezes ulceradas na sua superfície (Fig. 1). A maioria dos casos descritos referem-se a lesões na região ano-genital, em doentes seropositivos para VIH (Fig. 2). ${ }^{7}$ Numa série de doentes com herpes genital, a prevalência estimada de apresentações atípicas hipertróficas foi de $4,8 \% .^{8}$

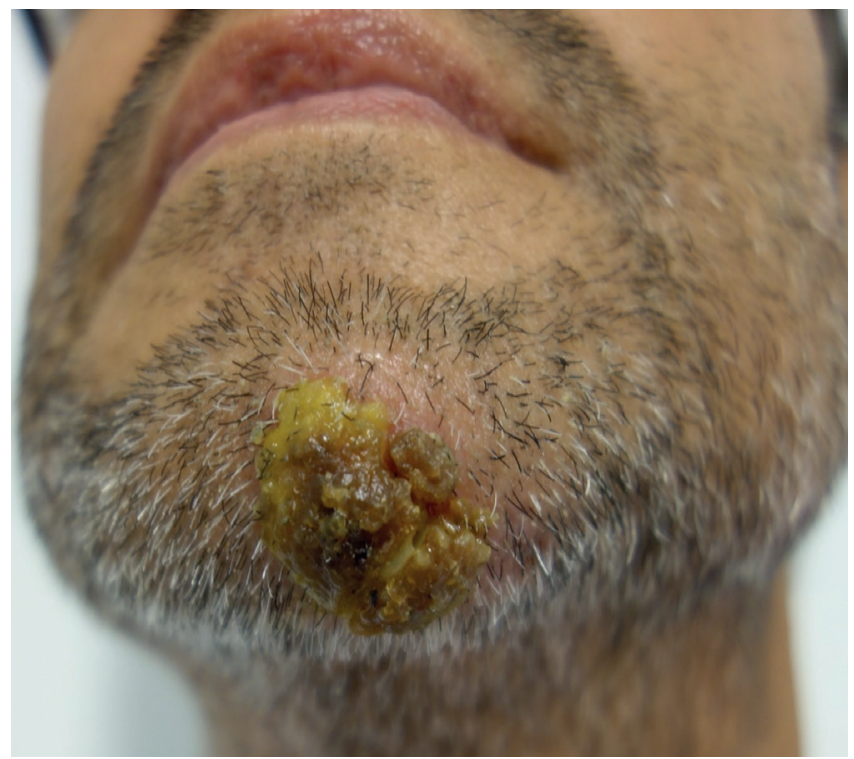

Figura 1 - Lesão hipertrófica herpética da região da barba em doente transplantado renal.

$\mathrm{Na}$ origem destas lesões parece estar um processo de desregulação imunitária, mediado por citocinas produzidas por linfócitos T helper tipo 2, que promove a hiperplasia da epiderme. Este fenómeno é independente do estadio da infeção por $\mathrm{VIH}$, podendo ser observados em indivíduos com contagens de linfócitos CD4+ normais ou

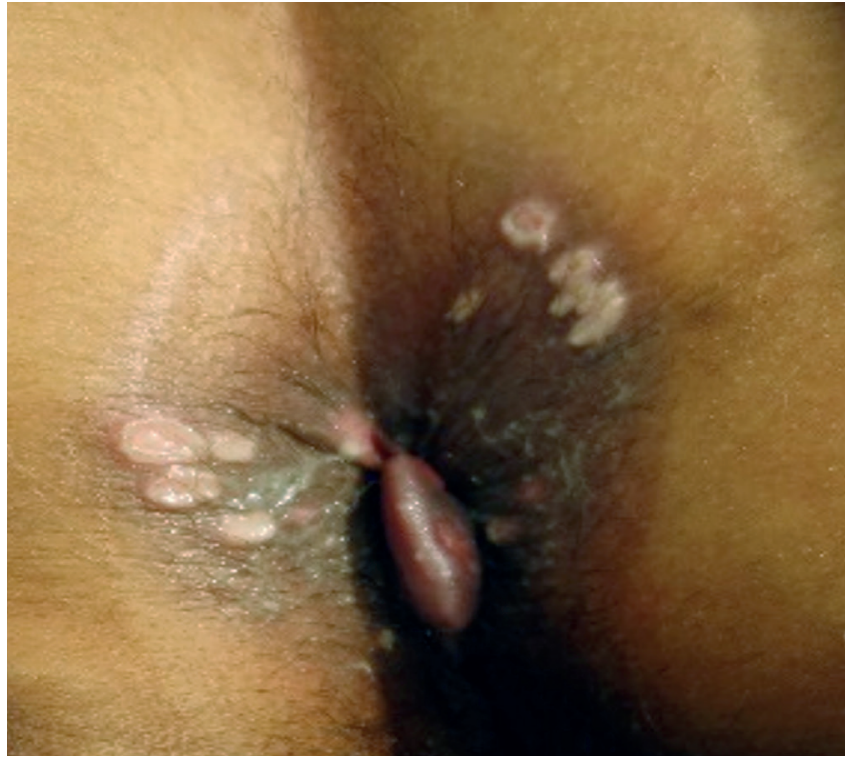

Figura 2 - Lesão hipertrófica herpética da região ano-genital em doente com infeção VIH, sem TARV.

baixas, bem como na presença ou ausência de terapêutica anti-retroviral (TARV). Estão ainda descritos casos no contexto da síndrome inflamatória de reconstituição imune (SIRI), em provável relação com uma resposta imunitária inapropriada. ${ }^{9}$

O exame histopatológico de biópsias cutâneas é importante para o diagnóstico diferencial e identifica hiperplasia pseudo-epiteliomatosa, células gigantes multinucleadas e um denso infiltrado de linfócitos e plasmócitos. ${ }^{10}$ Contudo, a sua interpretação é por vezes complexa, dado que as alterações citopáticas herpéticas podem estar obscurecidas por um denso infiltrado inflamatório. ${ }^{11}$ O diagnóstico de infeção herpética hipertrófica deve basear-se na integração dos dados clínicos e histopatológicos, em conjunto com estudos de cultura viral, PCR e/ou imunohistoquímica. ${ }^{7}$

O diagnóstico diferencial entre estas lesões hipertróficas e um carcinoma espinocelular é, com frequência, difícil. $O$ índice de suspeição para uma lesão neoplásica aumenta na presença de uma massa exofítica de grandes dimensões, de rápido crescimento, com ulceração extensa ou linfadenopatia associada. ${ }^{11}$ Por vezes, os dois diagnósticos co-existem, sendo identificados focos de tecido neoplásico num substrato de lesão herpética hipertrófica. ${ }^{10}$ Outros diagnósticos diferenciais a considerar incluem condilomas acuminados gigantes (tumor de Buschke Lowenstein), lesões de sífilis secundária (condylomata lata), co-infeção pelos vírus herpes zoster ou citomegalovírus (CMV) e molusco contagioso. ${ }^{6}$

A terapêutica nos indivíduos com apresentações atípicas de infeção herpética é complexa, particularmente na presença de seropositividade para $\mathrm{VIH}$, requerendo maior tempo de tratamento e estando associada a uma 
importante taxa de resistência aos fármacos anti-virais comumente utilizados. ${ }^{12}$

Nos indivíduos imunocompetentes a resistência ao VHS é rara, mesmo quando utilizada terapêutica anti-viral supressora por longos períodos, estimando-se em 0,1\% a $0,6 \%$. Contudo, nos indivíduos com compromisso da imunidade há uma taxa de resistência significativa, com prevalências reportadas de $5 \%$ a $7 \% .^{13}$

Na terapêutica inicial está preconizada a utilização de um agente anti-viral análogo nucleósido, administrado oralmente, estando disponíveis como alternativas o aciclovir $400 \mathrm{mg}$ per os, 5 tomas diárias, durante 7-10 dias ou o valaciclovir 500-1000 mg per os, bid, durante 10 dias. ${ }^{13}$

Na ausência de melhoria clinicamente evidente após 10 dias consecutivos de tratamento, deve ser efetuada reavaliação clínica e equacionadas hipóteses diagnósticas alternativas. Após a revisão do diagnóstico, na presença de uma lesão herpética recalcitrante, deve ser presumida a presença de resistência farmacológica. Nestas situações deve ser realizada cultura viral, com teste de resistência a agentes anti-virais. Contudo, esta não está disponível na maioria dos hospitais e não deve atrasar o início de uma outra terapêutica presumivelmente eficaz. ${ }^{2}$

Cerca de 95\% das estirpes de VHS resistentes a aciclovir isoladas não exprimem timidina cinase ou a expressão é minima. ${ }^{14}$ Estas estirpes mantêm, contudo, a suscetibilidade aos anti-virais foscarnet e cidofovir, que não requerem a atividade da referida enzima. ${ }^{13}$ As posologias recomendadas são foscarnet $40 \mathrm{mg} / \mathrm{kg}$, ev, tid e cidofovir $5 \mathrm{mg} / \mathrm{kg}$, ev, uma administração semanal. A duração da terapêutica é determinada pela resolução clínica das lesões. ${ }^{13}$

A terapêutica tópica com imiquimod é uma alternativa no tratamento de lesões herpéticas recorrentes e/ou refratárias à terapêutica anti-viral. Este fármaco é um agonista do Toll-like receptor 7, mecanismo através do qual estimula a resposta imune mediada por células, não tendo um efeito anti-viral direto. ${ }^{15}$ Os seus efeitos imunomoduladores tornam-no uma estratégia terapêutica importante na presença de lesões herpéticas atípicas, em indivíduos com elevado risco de desenvolver resistência farmacológica. ${ }^{8}$ $\mathrm{Na}$ maioria dos casos descritos foi utilizado um esquema posológico de administração tópica de imiquimod a $5 \%$ três vezes por semana, sendo reportado um tempo até à cura das lesões cutâneas entre uma e 14 semanas. ${ }^{16} \mathrm{~A}$ terapêutica conjunta com imiquimod tópico e um fármaco anti-viral administrado per os é outra alternativa nestas lesões. ${ }^{17,18}$

Outras opções terapêuticas reportadas como eficazes em lesões herpéticas hipertróficas refratárias incluem a talidomida, o interferão gamma (IFN- $\gamma$ ) e a excisão cirúrgica, particularmente se tiverem grandes dimensões. ${ }^{10,19}$

A taxa de recorrência nos doentes com apresentação atípica de infeção pelo VHS é elevada, pelo que após a resolução das lesões é recomendável a administração profilática de terapêutica anti-viral, nas seguintes posologias: aciclovir 400 mg per os, bid-tid, ou valaciclovir 500 mg

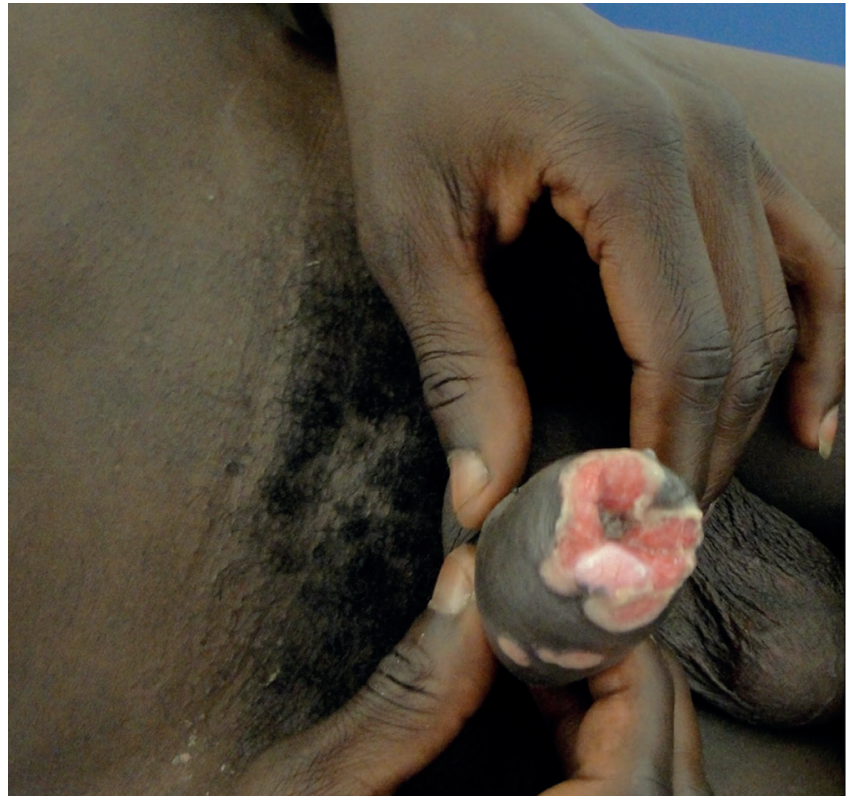

Figura 3 - Úlcera genital com mais de um mês de evolução em doente em estadio de SIDA.

per os, bid. ${ }^{13,20}$ A utilização destes fármacos mantém-se pertinente na presença de infeção prévia por estirpe de VHS resistente aos mesmos, na medida em que alguns trabalhos referem reversão da resistência após terapêutica com cidofovir. ${ }^{20}$

\section{ÚLCERAS CRÓNICAS}

Os doentes imunocomprometidos com infeção pelo VHS podem desenvolver lesões ulcerativas crónicas na região ano-genital, com elevada dimensão (Fig. 3). Estas lesões podem persistir por vários meses e a sua gravidade clínica correlaciona-se com o grau de imunossupressão. ${ }^{4}$

Uma úlcera genital crónica com evolução superior a um mês é um marcador de disfunção do sistema imunitário, sendo condição definidora de síndrome de imunodeficiência adquirida (SIDA) em doentes com infeção $\mathrm{VIH} .{ }^{21}$

A obtenção de biópsias de úlceras genitais atípicas tem um papel importante no diagnóstico, o qual é confirmado por cultura viral, imunohistoquímica e/ou PCR.

O diagnóstico diferencial de úlceras genitais atípicas é extenso, incluindo patologias com afeção cutânea de natureza infeciosa e neoplásica. Particularmente relevante é a exclusão da presença de carcinoma espinocelular, pelas suas implicações prognósticas e terapêuticas. Nos indivíduos seropositivos para VIH o diagnóstico diferencial deve também incluir sífilis, infeções por CMV e infeções parasitárias, enquanto nos indivíduos com transplante de órgão, as infeções por CMV devem ser preferencialmente consideradas. $^{22}$

A terapêutica com aciclovir ou valaciclovir é eficaz, requerendo contudo doses mais elevadas e uma maior duração da terapêutica: aciclovir 400 mg per os, 5 tomas diárias, 


\section{GEIDST}

durante 7-10 dias ou o valaciclovir 500-1000 mg per os, bid, durante 10 dias. ${ }^{13}$ Nos casos mais graves deve ser considerada a necessidade de internamento e terapêutica endovenosa. Nos doentes seropositivos para VIH, a TARV pode encurtar o tempo de resolução do quadro clínico, embora possam surgir novas lesões atípicas no contexto do SIRI. ${ }^{13}$ Caso a úlcera persista apesar da melhoria do sistema imunitário e da terapêutica com doses elevadas de aciclovir, devem ser consideradas as hipóteses de resistência farmacológica, de co-infeção com outro microrganismo e de um

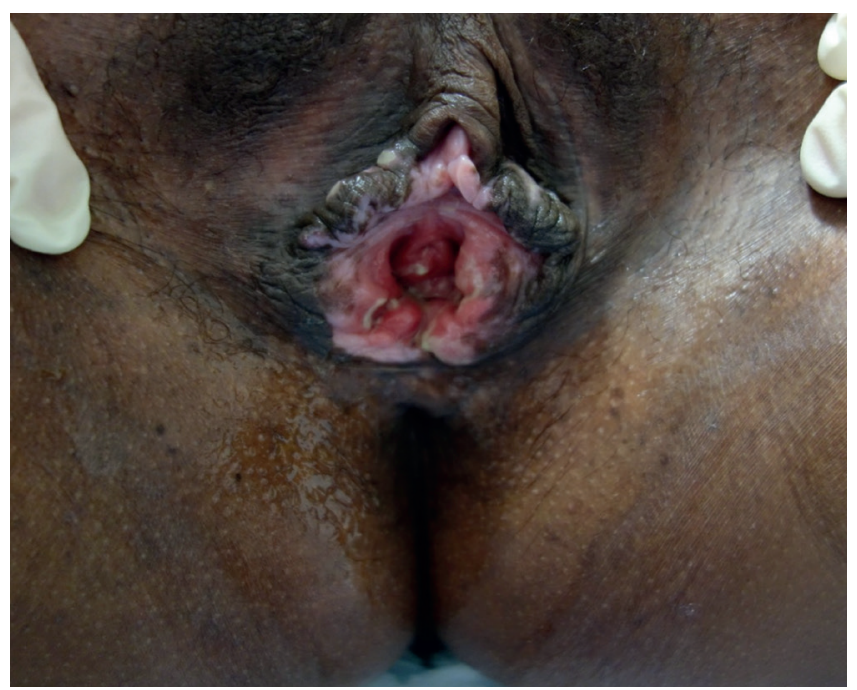

Figura 4 - Úlcera genital crónica, com co-infeção vaginal por CMV-VHS-2, em mulher com infeção VIH, com carga viral indetetável e contagem de linfócitos CD4+> 300 células $/ \mathrm{mm}^{3}$.

diagnóstico alternativo. Nestas situações, sempre que possível, deve ser efetuado estudo de resistência viral. Perante resistência à terapêutica anti-viral convencional, os fármacos foscarnet e cidofovir são alternativas eficazes, nas seguintes posologias: foscarnet $40 \mathrm{mg} / \mathrm{kg}$, ev, tid e cidofovir $5 \mathrm{mg} / \mathrm{kg}$, ev, uma administração semanal. ${ }^{13,20}$

Em raras circunstâncias, as formas de apresentação atípica resultam de infeção simultânea com outros microrganismos, entre os quais o CMV. ${ }^{22}$ Esta hipótese deve ser considerada perante úlceras genitais crónicas, de grandes dimensões, refratárias à terapêutica (Fig. 4). O recurso a biópsias é fundamental para o diagnóstico, mas a identificação das alterações citopáticas geradas pela infeção por
CMV é frequentemente difícil, sendo necessárias técnicas de PCR, cultura viral e/ou imunohistoquímica para efetuar o diagnóstico. ${ }^{22,23}$ A terapêutica com valganciclovir na posologia 900 mg, bid, revela-se eficaz. ${ }^{22,23}$

\section{FOLICULITE HERPÉTICA}

A foliculite herpética é uma manifestação rara da infeção pelo VHS. A razão do tropismo pelo folículo piloso não é conhecida. ${ }^{24}$ Os poucos casos descritos referem-se a indivíduos imunocompetentes, a maioria previamente saudável, e relatam envolvimento do couro cabeludo, da região genital e sicose herpética. ${ }^{24-27}$

Clinicamente, a forma de apresentação mais comum caracteriza-se por vesículas e/ou pústulas, com distribuição folicular. ${ }^{24}$ Contudo, a foliculite herpética caracteriza-se por um elevado espectro de apresentações clínicas, sendo frequente a inexistência de lesões caraterísticas da infeção pelo VHS, tornando o diagnóstico complexo. ${ }^{28}$

A maioria dos casos são incorretamente diagnosticados como infeção bacteriana ou fúngica, e apenas após o insucesso da terapêutica antibiótica e/ou anti-fúngica é considerada a hipótese de foliculite herpética. ${ }^{27}$

As biópsias cutâneas revelam efeitos virais citopáticos limitados à unidade pilossebácea, poupando a epiderme adjacente. ${ }^{24} \mathrm{Um}$ achado histopatológico característico é a presença de um infiltrado linfocítico em torno do folículo piloso. ${ }^{28}$ Os métodos de cultura viral, imunohistoquímica e/ou PCR, integrados com a informação clínica, permitem o diagnóstico. ${ }^{24}$

A terapêutica anti-viral com aciclovir e valaciclovir é eficaz, conduzindo à resolução das lesões cutâneas de foliculite num breve período. ${ }^{25-27}$ Os esquemas posológicos recomendados são semelhantes aos indicados para indivíduos imunocompetentes, com infeções não primárias e não complicadas: Aciclovir $800 \mathrm{mg}$ tid, durante dois dias ou valaciclovir 500 mg bid, durante três dias. ${ }^{13}$

\section{CONCLUSÃO}

As formas de apresentação atípica de infeção pelo vírus herpes simplex são cada vez mais frequentes na prática clínica, em consequência do crescente número de indivíduos imunossuprimidos. $\bigcirc$ diagnóstico diferencial é extenso e a resposta à terapêutica convencional é, por vezes, ineficaz. Perante apresentações clínicas atípicas, crónicas, recorrentes não deve ser esquecido o rastreio de infeção por VIH. 
Conflitos de interesse: Os autores declaram não possuir conflitos de interesse.

Suporte financeiro: $O$ presente trabalho não foi suportado por nenhum subsídio ou bolsa.

Confidencialidade dos dados: Os autores declaram ter seguido os protocolos do seu centro de trabalho acerca da publicação dos dados de doentes.

Protecção de pessoas e animais: Os autores declaram que os procedimentos seguidos estavam de acordo com os regulamentos estabelecidos pelos responsáveis da Comissão de lnvestigação Clínica e Ética e de acordo com a Declaração de Helsínquia da Associação Médica Mundial

Conflicts of interest: The authors have no conflicts of interest to declare.

Financing Support: This work has not received any contribution, grant or scholarship.

Confidentiality of data: The authors declare that they have followed the protocols of their work center on the publication of data from patients.

Protection of human and animal subjects: The authors declare that the procedures followed were in accordance with the regulations of the relevant clinical research ethics committee and with those of the Code of Ethics of the World Medical Association (Declaration of Helsinki).

\section{REFERÊNCIAS}

1. Gnann JW, Whitley RJ. Genital herpes. N Engl J Med. 2016; 375: 666-74.

2. Saverbrei A. Optimal management of genital herpes: current perspectives. Infect Drug Resist. 2016; 9:129141.

3. Looker KJ, Elmes JR, Gottlieb SL, Schiffer JT, Vickerman P, Turner KM, et al. Effect of HSV-2 infection on subsequent HIV acquisition: an updated systematic review and meta-analysis. Lancet Infect Dis. 2017; 17:1303-6.

4. Tyring SK, Carlton SS, Evans T. Herpes. Atypical clinical manifestations. Dermatol Clin. 1998; 16:783-8.

5. Swetter SM, Hill EL, Kern ER, Koelle DM, Posavad CM, Lawrence $W$, et al. Chronic vulvar ulceration in an immunocompetent woman due to acyclovir-resistant, thymidine kinase-deficient herpes simplex virus. J Infect Dis. 1998; 177:543-50.

6. Carrasco DA, Trizna Z, Colome-Grimmer M, Tyring SK. Verrucous herpes of the scrotum in a human immunodeficiency virus positive man: case report and review of the literature. J Eur Acad Dermatol Venereol. 2002; 16:511-5.

7. Ranu H, Lee J, Chio M, Sen P. Tumour-like presentations of anogenital herpes simplex in HIV-positive patients. Int J STD AIDS. 2011; 22:181-6

8. Leeyaphan C, Surawan TM, Chirachanakul P, Prasertworonun N, Punyaratabandhu P, Omcharoen V, et al. Clinical characteristics of hypertrophic herpes simplex genitalis and treatment outcomes of imiquimod: a retrospective observational study. Int J Infect Dis. 2015; 33:165-70.
9. Yudin $M H$, Kaul R. Progressive hypertrophic genital herpes in an $\mathrm{VIH}$-infected woman despite immune recovery on antiretroviral therapy. Infect Dis Obstet Gynecol. 2008:2008:592532.

10. Strehl JD, Mehlhorn G, Koch MC, Harrer EG, Harrer $\mathrm{T}$, Becjmann MW, et al. HIV-associated hypertrophic herpes simplex genitalis with concomitant early invasive squamous cell carcinoma mimicking advanced genital cancer: case report and literature review. Int J Gynecol Pathol. 2012; 31: 286-93.

11. Domfeh AB, Silasi DA, Lindo F, Parkash V. Chronic hypertrophic vulvar herpes simulating neoplasia. Int J Gynecol Pathol. 2012; 31:33-7.

12. Piret J, Boivin G. Resistance of herpes simplex viruses to nucleoside analogues: mechanisms, prevalen$\mathrm{ce}$, and management. Antimicrob Agents Chemother. 2011;55:459-72.

13. Patel R, Kennedy OJ, Clarke E, Geretti A, Nilsen A, Lautenschlager $S$, et al. 2017 European guidelines for the management of genital herpes. Int J STD AIDS. 2017; 28:1366-79.

14. Jiang $Y C$, Feng $H$, Lin $Y C$, Guo XR. New strategies against drug resistance to herpes simplex virus. Int J Oral Sci. 2016; 8:1-6.

15. Tandon S, Singh J, Sharma P, Sinha S. Recalcitrant hypertrophic herpes genitalis in HIV-infected patient successfully treated with topical imiquimod. Dermatol Ther. 2017; 30:e12479

16. Perkins $N$, Nisbet $M$, Thomas $M$. Topical imiquimod treatment of aciclovir-resistant herpes simplex disease: case series and literature review. Sex Transm Infect. $2011 ; 87: 292-5$.

17. Barbosa LN, Souto R, Furtado AL, Gripp AC, Daxbacher E. Association of oral acyclovir and imiquimod for the treatment of hypertrophic genital herpes simplex in HIV positive patients: report of two cases. An Bras Dermatol. 2011 ; 86:1043-5.

18. Matos D, Alves J, António AM, Coelho R, Bártolo E. Ulcerações genitais herpéticas recalcitrantes tratadas com imiquimod associado ao valaciclovir. Rev Soc Port Dermatol Venereol. 2014; 72:535-9.

19. Arinze F, Shaver A, Raffanti S. Surgical excision for recurrent herpes simplex virus 2 (HSV-2) anogenital infection in a patient with human immunodeficiency virus (HIV). Infection. 2017; 45:705-7.

20. Usoro A, Batts A, Sarria JC. Intravenous foscarnet with topical cidofovir for chronic refractory genital herpes in a patient with AIDS. J Investig Med High Impact Case Rep. 2015; 3:2324709615621095.

21. Kieselova K, Santiago F, Falhas C, Henrique M. Chronic penile ulcer as the first manifestation of HIV infection. BMJ Case Rep 2017; 2017: pii: bcr-2017221604.

22. Garib G, Hughey LC, Elmets CA, Cafardi JA, Andea AA. Atypical presentation of exophytic herpes simplex virus type 2 with concurrent cytomegalovirus infection: 
a significant pitfall in diagnosis. Am J Dermatopathol. $2013 ; 35: 371-6$.

23. Gouveia Al, Borges-Costa J, Soares-Almeida L, Sacramento-Marques $M$, Kutzner $H$. Herpes simplex virus and cytomegalovirus co-infection presenting as exuberant genital ulcer in a woman infected with human immunodeficiency virus. Clin Exp Dermatol. 2014; 39:915-7.

24. Böer A, Herder N, Winter K, Falk T. Herpes folliculitis: clinical, histopathological, and molecular pathologic observations. Br J Dermatol. 2006; 154:743-6.

25. Foti C, Calvario A, d'Ovidio R, Bonamonte D,
Scarasciulli ML, Conserva A, et al. Recalcitrant scalp folliculitis: a possible role of herpes simplex virus type 2. New Microbiol. 2005; 28:157-9.

26. Campanelli A, Marazza G, Stucki L, Abraham S, Prins $C$, Kaya $G$, et al. Fulminant herpetic sycosis: atypical presentation of primary herpetic infection. Dermatology. $2004 ; 208: 284-6$.

27. Al-Dhafiri SA, Molinari R. Herpetic folliculitis. J Cutan Med Surg. 2002; 6:19-22.

28. Bae-Harboe YS, Bhawan J, Demierre MF, Goldberg LJ. Herpes folliculitis masquerading as cutaneous lymphoma. Am J Dermatopathol. 2013; 35:663-5. 